\title{
Favorecimento de um trabalho interdisciplinar mediante elaboração de mapa conceitual e projeto elétrico residencial
}

Favoring of interdisciplinary work through elaboration of conceptual map and residential electrical project

Favorecimiento de un trabajo interdisciplinario mediante la elaboración de un mapa conceptual y proyecto eléctrico residencial

Guilherme Zoia Mapeli

ORCID: https://orcid.org/0000-0002-9082-9685 Instituto Federal de Educação, Ciência e Tecnologia Farroupilha, Brasil E-mail: rocegui@gmail.com

Jonas Cegelka da Silva

ORCID: https://orcid.org/0000-0002-8492-6702 Instituto Federal de Educação, Ciência e Tecnologia Farroupilha, Brasil E-mail: jonas.silva@iffarroupilha.edu.br

Raquel Maldaner Paranhos

ORCID: https://orcid.org/0000-0002-2720-2169 Instituto Federal de Educação, Ciência e Tecnologia Farroupilha, Brasil

E-mail: raquel.paranhos@iffarroupilha.edu.br

\begin{abstract}
Resumo
Muitas práticas escolares evidenciam apenas uma justaposição de disciplinas, em que cada professor, na sua aula, aborda alguns conceitos específicos, dificultando que os estudantes consigam transferir de forma espontânea os conhecimentos de uma disciplina à outra. Essas práticas, no terreno da multidisciplinaridade foram superadas num trabalho interdisciplinar entre as disciplinas de física e sistemas prediais, do terceiro ano do curso técnico em edificações integrado ao ensino médio do Instituto Federal de Educação, Ciência e Tecnologia Farroupilha, Campus Santa Rosa/RS. Mediante elaboração, desenvolvimento e avaliação de uma Unidade de Ensino Potencialmente Significativa (UEPS) sobre os circuitos elétricos simples, os professores de ambas as disciplinas, de forma conjunta, desenvolveram os conceitos específicos de suas disciplinas de forma integrada, considerando que estes são convergentes. A partir dos resultados construídos, o texto que segue tem o objetivo de investigar quais as implicações de um trabalho interdisciplinar entre as disciplinas de física e de sistemas prediais para a aprendizagem significativa dos estudantes sobre circuitos elétricos simples. Em alguns passos da UEPS os estudantes elaboraram mapas conceituais interdisciplinares e construíram um projeto elétrico residencial, tendo suas casas como referência. A construção desses instrumentos foi assessorada por ambos os professores, sendo utilizados como instrumento avaliativo pelas duas disciplinas. Tanto no mapa conceitual quanto no projeto elétrico, os estudantes demonstraram indícios de aprendizagem significativa, compartilhando os conhecimentos das disciplinas, o que ratifica a concretização e a importância de um trabalho interdisciplinar para o favorecimento da aprendizagem significativa.

Palavras-chave: Integração curricular; Interdisciplinaridade; Aprendizagem significativa.
\end{abstract}

\begin{abstract}
Many school practices show just a juxtaposition of disciplines, in which each teacher, in his/her class, addresses some specific concepts, making it difficult for students to spontaneously transfer knowledge from one discipline to another. These practices were overcome in an interdisciplinary work between the disciplines of physics and building systems of the third year of the technical course in buildings integrated to the high school of the "Instituto Federal de Educação, Ciência e Tecnologia Farroupilha, Campus Santa Rosa/RS". Through the elaboration, development, and evaluation of a Potentially Meaningful Teaching Units (PMTUS) about simple electrical circuits, teachers of both disciplines developed together the specific concepts of their disciplines in an integrated manner, considering that these are convergent. Based on the results, the following text aims to investigate the implications of interdisciplinary work between the disciplines of physics and building systems for the students' meaningful learning about simple electrical circuits in some steps of the PMTUS, the students elaborated interdisciplinary conceptual maps and built a residential electrical project, with their houses as reference. The construction of these instruments was assisted by both teachers, and they were used as evaluative instruments by both disciplines. Both in the conceptual map and in the electrical
\end{abstract}


project, students showed signs of meaningful learning, sharing the knowledge of the disciplines, which ratifies the achievement and the importance of an interdisciplinary work to promote meaningful learning.

Keywords: Curricular integration; Interdisciplinarity; Meaningful learning.

\begin{abstract}
Resumen
Muchas prácticas escolares evidencian sólo una yuxtaposición de asignaturas, en la que cada profesor, en su clase, aborda algunos conceptos específicos, dificultando que los estudiantes consigan transferir de forma espontánea los conocimientos de una asignatura a otra. Estas prácticas, en el terreno de la multidisciplinariedad, fueron superadas en un trabajo interdisciplinario entre las asignaturas de física y sistemas prediales, del tercer año del curso técnico en edificaciones integrado a la enseñanza secundaria del Instituto Federal de Educação, Ciência e Tecnologia Farroupilha, Campus Santa Rosa/RS. Mediante la elaboración, desarrollo y evaluación de una Unidad de Enseñanza Potencialmente Significativa (UEPS) sobre los circuitos eléctricos simples, los profesores de ambas asignaturas, de forma conjunta, desarrollaron los conceptos específicos de sus asignaturas de forma integrada, considerando que éstos son convergentes. A partir de los resultados construidos, el texto que sigue tiene el objetivo de investigar cuáles son las implicaciones de un trabajo interdisciplinario entre las asignaturas de física y de sistemas prediales para el aprendizaje significativo de los estudiantes sobre circuitos eléctricos simples. En algunos pasos de la UEPS los estudiantes elaboraron mapas conceptuales interdisciplinarios y construyeron un proyecto eléctrico residencial, tomando sus casas como referencia. La construcción de estos instrumentos fue asesorada por ambos profesores, siendo utilizados como instrumento evaluativo por las dos asignaturas. Tanto en el mapa conceptual como en el proyecto eléctrico, los estudiantes demostraron indícios de un aprendizaje significativo, compartiendo los conocimientos de las asignaturas, lo que ratifica la concretización y la importancia de un trabajo interdisciplinario para el favorecimiento del aprendizaje significativo.
\end{abstract}

Palabras clave: Integración curricular; Interdisciplinariedad; Aprendizaje significativo.

\title{
1. Introdução
}

Os fenômenos elétricos despertam a curiosidade dos sujeitos, mas ao mesmo podem causar acidentes graves. Desde pequenos, as pessoas sentem os pelos eriçados ao vestirem uma roupa de lã e ouvem pequenos estalos quando se encostam a outras pessoas. Esses efeitos são produzidos pelas cargas elétricas em repouso, a conhecida eletrostática. Quando as cargas elétricas são submetidas a uma diferença de potencial elétrico, gerada por uma pilha, por exemplo, elas desenvolvem um movimento ordenado, que corresponde à corrente elétrica. E é graças a eletrodinâmica que os dispositivos elétricos funcionam quando conectados às tomadas.

No âmbito do Instituto Federal Farroupilha, Campus Santa Rosa, os estudantes do curso técnico em edificações integrado ao ensino médio têm, na grade curricular de física, o estudo da eletricidade ao longo do terceiro ano, com uma carg a horária de 3h/a por semana. Diferentemente do que acontece na maior parte das realidades, iniciou-se o estudo pela eletrodinâmica (ao invés da eletrostática) por dois motivos. O primeiro deles tem a ver com o fato da eletrodinâmica caracterizar fenômenos elétricos percebidos pelos estudantes, possibilitando uma relação daquilo que está sendo estudado ao seu cotidiano, mediante aplicação dos conceitos ao funcionamento dos dispositivos eletrônicos.

O segundo motivo dessa adequação do conteúdo vem do fato que os estudantes, na mesma série do curso, têm a disciplina de sistemas prediais, com uma carga horária semanal de 2h/a, contemplando, na ementa, dentre outros, noções de instalações elétricas residenciais, equipamentos básicos de eletricidade e normas técnicas de instalações elétricas prediais.

E essa complementariedade das ementas das duas disciplinas se tornou consciente aos professores a partir do ano de 2019, momento em que eles começaram a estruturar uma Unidade de Ensino Potencialmente Significativa (UEPS) sobre os circuitos elétricos, a ser desenvolvida de forma interdisciplinar. As UEPS correspondem a sequências didáticas, teoricamente fundamentadas, voltadas à aprendizagem significativa, com potencial para estimular a pesquisa diretamente voltada à sala de aula (Moreira, 2011).

Os passos das UEPS incluem definição do conteúdo; identificação dos conhecimentos prévios dos estudantes; proposição de situações em nível introdutório; apresentação do conhecimento possibilitando o princípio da diferenciação progressiva; apresentação de situações mais complexas, promovendo a integração reconciliadora; discussão de situações mais 
gerais e inclusivas, novamente buscando a diferenciação progressiva; busca de evidências de aprendizagem significativa (Moreira, 2016).

A UEPS está fundamentada na Teoria da Aprendizagem Significativa, cujo processo tem como essência o fato de as ideias expressadas simbolicamente estarem relacionadas de maneira não-arbitrária e substantiva àquilo que o estudante já sabe, a algum aspecto relevante existente na sua estrutura cognitiva, por exemplo, uma imagem, um símbolo, um conceito ou uma proposição (Ausubel, 1968).

A finalidade de propor uma UEPS interdisciplinar, com vistas ao favorecimento de uma aprendizagem significativa sobre os circuitos elétricos é convergente com a proposta de currículo integrado, numa perspectiva de formação politécnica e omnilateral, já que este

Não diz respeito somente a articulação entre formação geral e profissional. Isso significa que sua práxis deve se sustentar no desenvolvimento do pensamento complexo, na experimentação, no trabalho como prática educativa e no contexto no qual o discente está inserido, para assim ter como resultado uma aprendizagem significativa, em uma tentativa constante de interação entre as diversas áreas de conhecimento (Dália \& Frazão, 2017, p. 169).

Embora todos os passos da UEPS tenham sido estabelecidos a partir de reuniões de planejamento coletivo entre os professores, a etapa anterior - e concomitante também -consistiu em uma revisão bibliográfica em periódicos científicos e dissertações e teses, abrangendo o período dos últimos dez anos. Esta etapa é importante na medida em que ajuda elucidar o que já se tem publicado sobre a temática, apontando caminhos para delinear a pesquisa.

Dessa revisão bibliográfica foi possível pré-selecionar 22 artigos e 02 dissertações com foco semelhante a esta investigação. A partir de uma leitura exploratória dessas obras 07 artigos foram selecionados para uma leitura analítica, além das 02 dissertações (Gil, 2002). Esses trabalhos foram organizados em três categorias: exploração de atividades/recursos experimentais; práticas interdisciplinares e; concepções alternativas, as quais reforçam a importância da proposição desta UEPS interdisciplinar para o favorecimento de uma aprendizagem significativa dos conceitos da eletricidade, considerando as preconcepções dos estudantes frente a alguns conceitos, como corrente, resistência e tensão elétrica.

A proposição da UEPS enseja uma modificação na prática pedagógica das disciplinas de física e de sistemas prediais considerando que a integração curricular se dá no processo de ensino-aprendizagem, o que "implica bem mais que um currículo diferenciado ou diversificado, implica em educadores e em metodologias contínuas que fazem o ensino e a aprendizagem de forma a se integrar as dimensões da ciência, do trabalho, da cultura e da tecnologia" (Cruz Sobrinho, 2017, p. 106).

O favorecimento de atividades interdisciplinares foi um indicativo bastante forte entre as disciplinas de física e sistemas prediais pela proximidade das ementas. Além disso, outro aspecto pertinente que motivou a construção da UEPS é a complexidade dos conceitos atrelados à eletricidade. Trabalhos como os de Solano et al. (2002) e Dorneles, Araújo e Veit (2006) apresentam algumas dificuldades de aprendizagem dos estudantes para estes tópicos, destacando as concepções prévias dos mesmos como desfavoráveis à aprendizagem.

Da mesma forma, Pozo e Crespo (2009) destacam algumas das ideias e dificuldades de aprendizagem dos estudantes relacionadas com a eletricidade. Dentre elas os autores salientam que os estudantes: (i) têm dificuldades para interpretar a representação gráfica de um circuito elétrico; (ii) tendem a interpretar a diferença de potencial como uma propriedade da corrente elétrica; (iii) compreendem as pilhas como armazenadores de eletricidade; (iv) não veem a necessidade de fechar um circuito para que haja uma corrente elétrica e; (v) concebem a corrente elétrica como um fluido material que é consumido pelas lâmpadas. 
A organização de uma Unidade de Ensino Potencialmente Significativa, conforme detalhado no tópico seguinte, favorece a construção de uma aprendizagem significativa da eletricidade na medida em que propicia que os conceitos sejam desenvolvidos, elaborados e diferenciados em decorrência de múltiplas interações. Nessa organização, consideram-se os princípios da diferenciação progressiva e da reconciliação integrativa. O primeiro deles estabelece que o conteúdo deve ser iniciado com a apresentação das ideias mais gerais e inclusivas, as quais devem ser progressivamente diferenciadas em termos de detalhe e especificidade. O segundo princípio assegura que o material instrucional deve explorar a relação entre as ideias, apontando semelhanças e diferenças significativas (Moreira \& Masini, 1982).

Para o estudo dos conceitos abrangentes da UEPS, o planejamento das aulas baseou-se na teoria da aprendizagem significativa (Ausubel, 1968; 2003) e significativa crítica de Moreira (2012), de modo a considerar os princípios da interação social e do questionamento, da desaprendizagem e da diversidade de estratégias, adotando diversas estratégias facilitadoras que possibilitaram a redução da narrativa enquanto estratégia de ensino. Dentre essas estratégias, os estudantes trabalharam em grupos, discutiram conceitos, levantaram questionamentos.

Assumindo as premissas de uma Unidade de Ensino Potencialmente Significativa, embasada na teoria da Aprendizagem Significativa e considerando os resultados da busca bibliográfica, destaca-se que o objetivo da investigação reportada neste excerto é investigar possíveis indícios de aprendizagem significativa dos estudantes sobre os circuitos elétricos mediante uma abordagem interdisciplinar entre as disciplinas de física e de sistemas prediais. Para isso, serão considerados dois instrumentos avaliativos pertencentes a UEPS: mapa conceitual interdisciplinar e projeto elétrico residencial.

\section{Metodologia}

Como já apresentado, a investigação interdisciplinar é fruto da elaboração e desenvolvimento de uma Unidade de Ensino Potencialmente Significativa sobre circuitos elétricos, aplicada nas aulas de física e sistemas prediais, pelos próprios professores, a estudantes do terceiro ano do ensino médio. Em 2019 ocorreu a validação dos instrumentos numa intervenção com uma turma de 29 estudantes. Com essa validação, em 2020 a UEPS foi desenvolvida em outra turma de mesmo número de estudantes. E é dessa segunda intervenção didática que este artigo é escrito.

A investigação é do tipo estudo de caso e a análise é predominantemente qualitativa, em que a interpretação dos dados construídos é realizada pelos pesquisadores, com base em referencial teórico específico (Pereira et al, 2018). Sobre os passos da UEPS acerca dos circuitos elétricos (Silva, 2018), vale destacar as atividades propostas.

Buscando identificar os subsunçores presentes na estrutura cognitiva dos estudantes (passo dois ${ }^{1}$ ), foi aplicado um teste de múltipla escolha contendo 12 questões, adaptado de Silveira, Moreira e Axt (1989). Além deste, os estudantes precisaram fazer, esquematicamente, o desenho de um circuito elétrico para conseguir acender uma lâmpada com uma pilha.

Para o desenvolvimento do terceiro passo da UEPS, que corresponde à apresentação de situações introdutórias amplas, os estudantes assistiram ao vídeo curto-circuito elétrico causa incêndio ${ }^{2}$, o qual aborda os riscos da utilização de benjamim (tê) nas residências. A partir do vídeo, algumas questões debatidas foram: o que significa um curto-circuito em uma instalação elétrica? Qual a função dos disjuntores em uma instalação elétrica residencial? Por que a utilização do tê causa uma sobrecarga nos fios? O que significa a expressão sobrecarga? Todos os eletrodomésticos necessitam de uma tomada de uso exclusivo? A fiação elétrica pode ser a mesma instalada em toda a casa, para todos os equipamentos?

Ainda no passo três, mas com indicativo do seguinte, ao final do diálogo, foi solicitado aos estudantes que escolhessem, em suas casas, cinco eletrodomésticos e anotassem o valor de suas potências elétricas. Esses dados foram

\footnotetext{
${ }^{1}$ Vale destacar que o passo um da UEPS corresponde à escolha do tópico a ser estudado. No caso da investigação, são os circuitos elétricos simples.

${ }^{2}$ Vídeo disponível no endereço https://www.youtube.com/watch?v=Tw_0iGhxLtg.
} 
utilizados para o estudo da simulação do consumo de energia elétrica residencial. Além disso, os estudantes deveriam fazer um croqui da planta baixa de suas casas, explicitando as dimensões dos cômodos, o número de tomadas, os pontos de iluminação e o número e o valor dos disjuntores. Essas informações são essenciais para a construção do projeto elétrico residencial, um dos focos deste escrito.

Depois de se ter abordado tópicos mais gerais sobre os circuitos elétricos, o próximo passo da UEPS compreendeu o estudo do conteúdo específico, construindo conceitos como corrente elétrica, tensão elétrica, potência elétrica, associação de resistores elétricos, condutores elétricos, fornecimento de energia elétrica e dimensionamento dos circuitos de distribuição.

O quinto passo da UEPS, com vistas a promover a reconciliação integradora dos conceitos estudados, consistiu na exploração de simulações computacionais sobre instalações elétricas, associação de resistores e elementos constituintes dos circuitos elétricos simples. Dentre as simulações trabalhadas, destaque para: kit de Construção de Circuito $(A C+D C)^{3}$, circuito bateria-resistor $^{4}$ e laboratório virtual - EPT ${ }^{5}$.

A diferenciação progressiva dos conceitos abordados (passo seis) foi explorada na construção dos projetos elétricos residenciais, numa discussão comparativa com as atividades realizadas nos passos anteriores. Vale ressaltar que esse projeto foi orientado pelos professores ao longo das aulas, sempre num movimento de ir-e-vir, com apontamentos, sugestões e questionamentos.

Para a elaboração do projeto elétrico os estudantes precisaram fazer um croqui da planta baixa com as dimensões dos cômodos e construir tabelas (retomando os dados coletados no passo três), contendo, para cada cômodo, a área, o perímetro, a potência de iluminação, o número de tomadas e a potência das tomadas de uso geral e das de uso específico. Precisaram também dividir a instalação predial em circuitos e definir a potência e a corrente de cada circuito terminal, estipulando qual o disjuntor adequado a cada circuito. Além disso, estabeleceram o dimensionamento dos condutores e dos eletrodutos, além de representarem o projeto elétrico na planta baixa. Na representação dessa planta baixa, necessitavam indicar tomadas, interruptores, pontos de iluminação, quadro de distribuição, eletrodutos e condutores. Todos esses passos realizados atenderam a norma específica NBR 5410: instalações elétricas de baixa tensão (ABNT, 2004), a qual estabelece que, para edificações residenciais:

- A potência de iluminação deve ser de, no mínimo $100 \mathrm{VA}$ para cômodos com área menor/igual a $6 \mathrm{~m}^{2}$; para cômodos com área maior, deve ser de, no mínimo $100 \mathrm{VA}$ para os primeiros $6 \mathrm{~m}^{2}$, mais $60 \mathrm{VA}$ para cada aumento de $4 \mathrm{~m}^{2}$ inteiros.

- O número de tomadas de uso geral para a cozinha e lavanderias deve ser de um ponto de tomada a cada 3,5 $\mathrm{m}$ de perímetro (independente da área). Para os demais cômodos ou dependências com área menor/igual a $6 \mathrm{~m}^{2}$, no mínimo um ponto de tomada. Quando os cômodos/dependências possuírem área maior que $6 \mathrm{~m}^{2}$, no mínimo um ponto de tomada para cada $5 m$ de perímetro.

- A potência das tomadas de uso geral deve obedecer, para banheiro, cozinha/copa e lavanderia, no mínimo 600 VA por ponto de tomada (até três tomadas), mais 100 VA para cada tomada excedente. Para os demais cômodos/dependências, no mínimo 100 VA por ponto de tomada. Para as tomadas de uso específico deve ser atribuída a potência do equipamento que será ligado a ela. Esta potência será obtida no equipamento ou em normas técnicas das concessionárias de energia local, como por exemplo, da Companhia Paulista de Força e Luz ${ }^{6}$ (CPFL). Já para a definição do disjuntor necessário a cada circuito, é preciso considerar o fator de potência que, para a iluminação é 1,0 e para as tomadas de uso geral é 0,8 .

\footnotetext{
${ }^{3}$ Simulação disponível em https://phet.colorado.edu/pt_BR/simulation/legacy/circuit-construction-kit-ac.

${ }^{4}$ Simulação disponível em https://phet.colorado.edu/pt_BR/simulation/legacy/battery-resistor-circuit.

${ }^{5}$ Simulação disponível em http://eptvirtual.florianopolis.ifsc.edu.br/cice/lab.html.

${ }^{6}$ Norma disponível em http://sites.cpfl.com.br/documentos-tecnicos/GED-13.pdf.
} 
A busca por evidências de aprendizagem significativa se deu mediante duas provas interdisciplinares. Um exemplo de questão que os estudantes responderam foi: na elaboração do projeto elétrico, você precisou dimensionar os circuitos $e$ instalar um disjuntor adequado. Sendo o disjuntor um dispositivo de proteção, ele deve suportar uma ddp máxima nominal. Daí vem, por exemplo, que seus valores podem ser de $10 \mathrm{~V}, 25 \mathrm{~V}$ e $40 \mathrm{~V}$. Essa afirmação está correta? Se sim, comente. Se não, justifique o que há de errado.

Além das provas interdisciplinares, o mapeamento conceitual foi outro instrumento utilizado para a identificação de indícios de aprendizagem significativa. Conforme os conceitos foram sendo estudados, os estudantes construíram um mapa conceitual interdisciplinar, sendo estimulados a pensarem as relações conceituais entre as duas disciplinas. Destaca-se que mapas conceituais correspondem a "diagramas hierárquicos que procuram refletir a organização conceitual de uma disciplina ou parte de uma disciplina" (Moreira \& Masini, 1982, p. 45).

Importante sinalizar também que, no ano de 2020, em função da pandemia do Coronavírus (Covid-19), a pesquisa seguiu com as atividades de ensino não presenciais (remotas). Mesmo assim a UEPS foi desenvolvida mediante utilização de tecnologias de informação e comunicação, com alguns ajustes (especialmente no passo seis). Apesar de todas as dificuldades em desenvolver aulas remotamente e on-line, sempre se teve como princípio não torná-las maçantes, instrucionistas e unidirecionais (Pimentel \& Carvalho, 2020).

Uma vez que a UEPS é composta por vários passos e diversos instrumentos foram utilizados com vistas à identificação de evidências de aprendizagem significativa, no texto que segue será explorada apenas a análise dos instrumentos construídos nos passos três e seis, que correspondem ao mapeamento conceitual e à elaboração do projeto elétrico residencial. Nas análises que seguem, os estudantes serão identificados genericamente por estudante $01,02,03$, etc., com vistas a preservar suas identidades.

\section{Resultados e Discussão}

Da forma como já explicitado, a seguir será apresentada a análise de dois instrumentos resultantes da UEPS: mapas conceituais e projeto elétrico. Ambos foram realizados de forma individual, com assessoramento dos professores. Inicia-se pela análise dos mapas conceituais.

\section{Mapas Conceituais}

No caso da UEPS, esse instrumento objetivou verificar de que forma os estudantes relacionam os conceitos de cada disciplina, mas também como os integram, na perspectiva do trabalho interdisciplinar. No entanto, como se vê ao longo da análise, os mapas construídos pelos estudantes nem sempre se caracterizam como conceituais, da forma como proposto por Novak \& Cañas (2010), uma vez que incluem frases, exemplos, equações e gráficos. Ainda assim, esse instrumento é rico no sentido de tornar explícitas algumas relações que os estudantes fazem dos conceitos. Ao longo da construção dos mapas, os estudantes foram orientados a tornarem explícitas as relações entre os conceitos, fazendo um esforço de representar ligações cruzadas, sem esquecer de inserir as palavras de ligação entre os conceitos, uma vez que estas dão sentido às relações conceituais.

A Figura 1 mostra o mapa conceitual interdisciplinar construído pelos professores. Este instrumento não foi utilizado como padrão/correto, uma vez que os mapas são idiossincráticos, mas teve duas funções essenciais. Uma delas foi o próprio favorecimento da abordagem interdisciplinar, mediante planejamento coletivo e; a segunda foi estabelecer algumas relações importantes que poderiam ser verificadas nos mapas dos estudantes. 
Figura 1. Mapa conceitual sobre eletricidade, numa perspectiva interdisciplinar entre física e sistemas prediais.

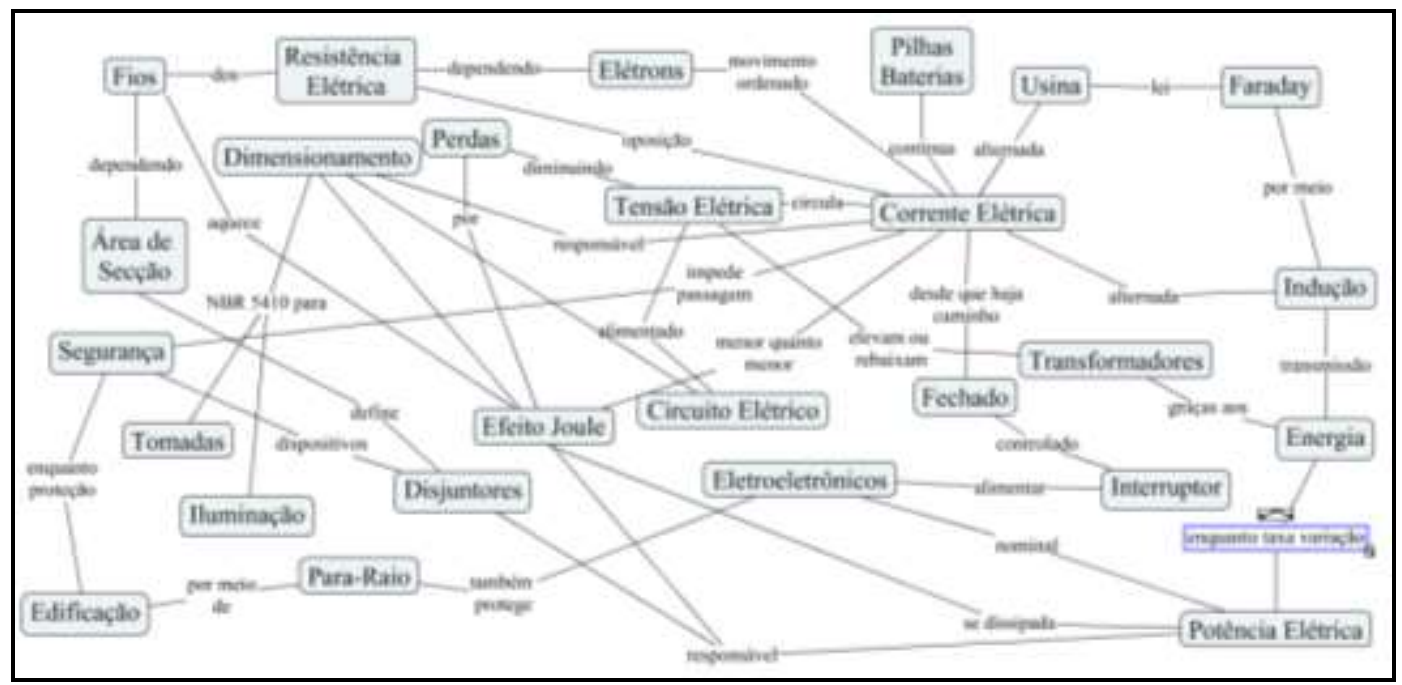

Fonte: Silva et al. (2020, p. 445).

Ao final da construção do mapa conceitual dos estudantes, foi possível organizá-los em três categorias: satisfatórios, parcialmente satisfatórios e insatisfatórios. Aqueles mapas categorizados como satisfatórios (07, no total) apresentam um bom número de conceitos, ligações pertinentes/corretas entre eles e relações entre as disciplinas. Por sua vez, os parcialmente satisfatórios (12, no total) apresentam um bom número de conceitos, mas existem ligações incorretas entre eles, além de haver pouca relação entre as disciplinas. Já os mapas insatisfatórios (10, no total) não apresentam número suficiente de conceitos, além de não deixarem clara a relação entre eles e também não apresentam relação entre as disciplinas.

As Figuras 2 e 3 são exemplos de mapas satisfatórios. Na primeira delas, é possível perceber um número significativo de conceitos de ambas as disciplinas. Esses se relacionam de forma satisfatória, formando novos conceitos e relações, as quais são enriquecidas por meio de ligações que contém termos conectivos coerentes. Por mais desenvolvidos que sejam os conceitos, o mapa não deixa de apresentar fórmulas e simbologias técnicas, utilizados na elaboração do projeto elétrico residencial, o que reforça a interdisciplinaridade. 
Research, Society and Development, v. 10, n. 3, e15310313296, 2021

(CC BY 4.0) | ISSN 2525-3409 | DOI: http://dx.doi.org/10.33448/rsd-v10i3.13296

Figura 2. Mapa conceitual sobre eletricidade categorizado como satisfatório.

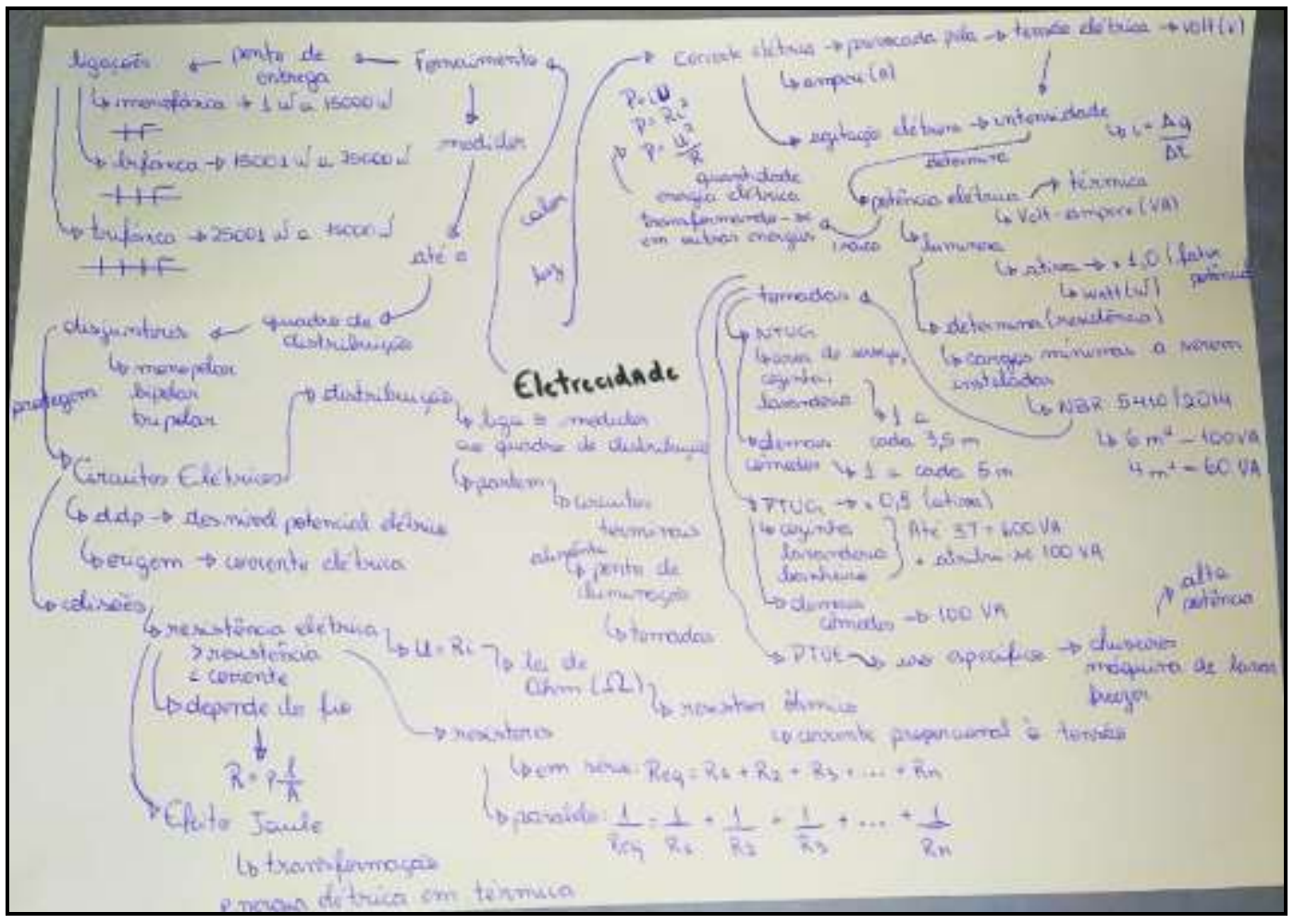

Fonte: Estudante A10

Figura 3. Mapa conceitual sobre eletricidade categorizado como satisfatório.

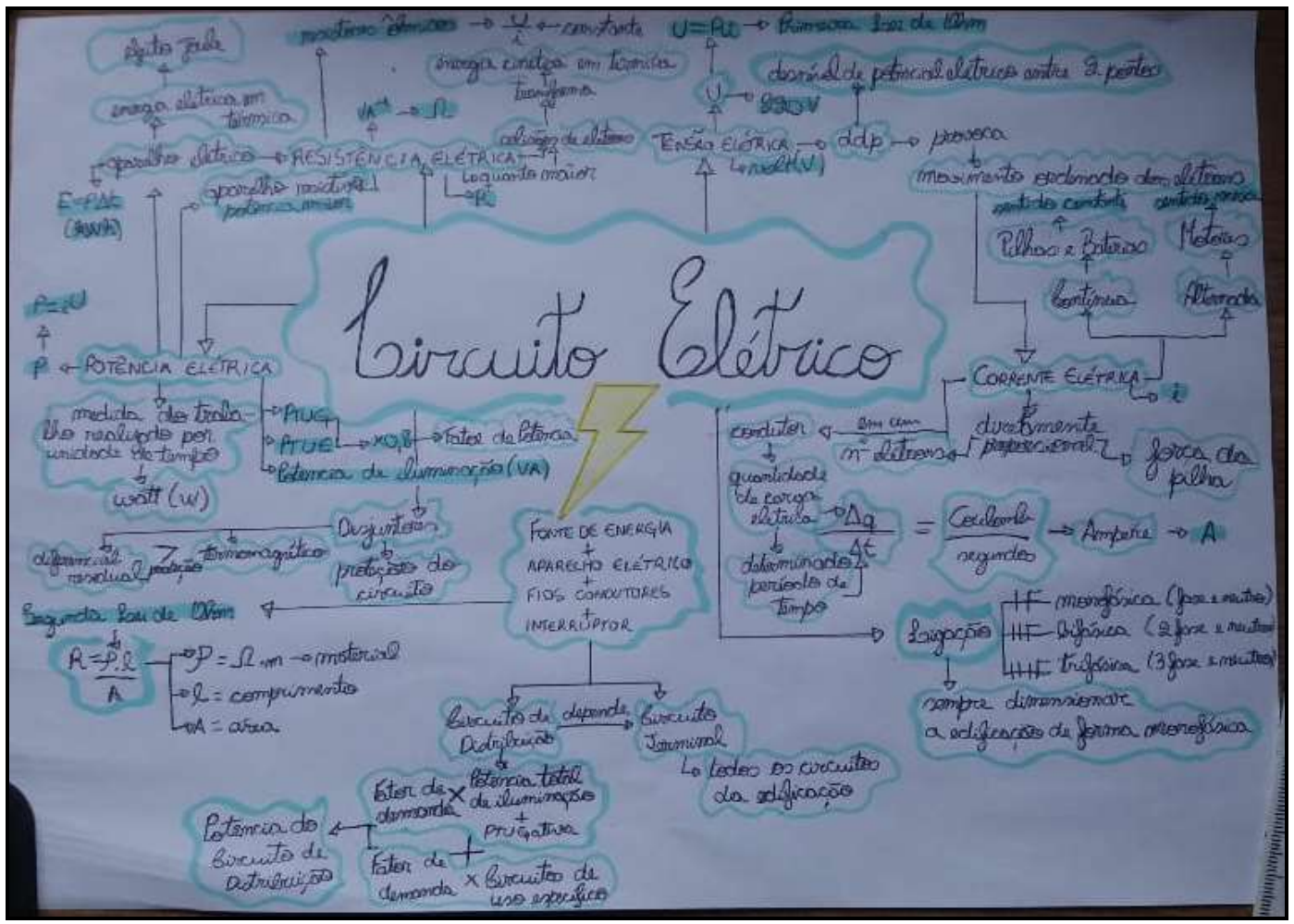

Fonte: Estudante A17.

A Figura 3, acima, ilustra um mapa conceitual satisfatório, que apresenta um número significativo de conceitos, corretos e pertencentes às duas disciplinas. Os conteúdos são bem relacionados, trazendo uma sequencialidade dos assuntos 
gerais (propriedades) e dos assuntos técnicos (normas e componentes) de maneira integrada e coerente, fazendo o uso de termos conectivos adequados.

Os dois mapas caracterizados como satisfatórios exprimem uma organização e relações que permitem observar o princípio da diferenciação progressiva na construção do conhecimento dos estudantes. Isso porque esse princípio fundamenta que "a maioria da aprendizagem e toda a retenção e a organização das matérias é hierárquica por natureza, procedendo de cima para baixo em termos de abstração, generalidade e inclusão" (Ausubel, 2003, p. 6).

As Figuras 4 e 5 representam mapas parcialmente satisfatórios.

Figura 4. Mapa conceitual sobre eletricidade categorizado como parcialmente satisfatório.

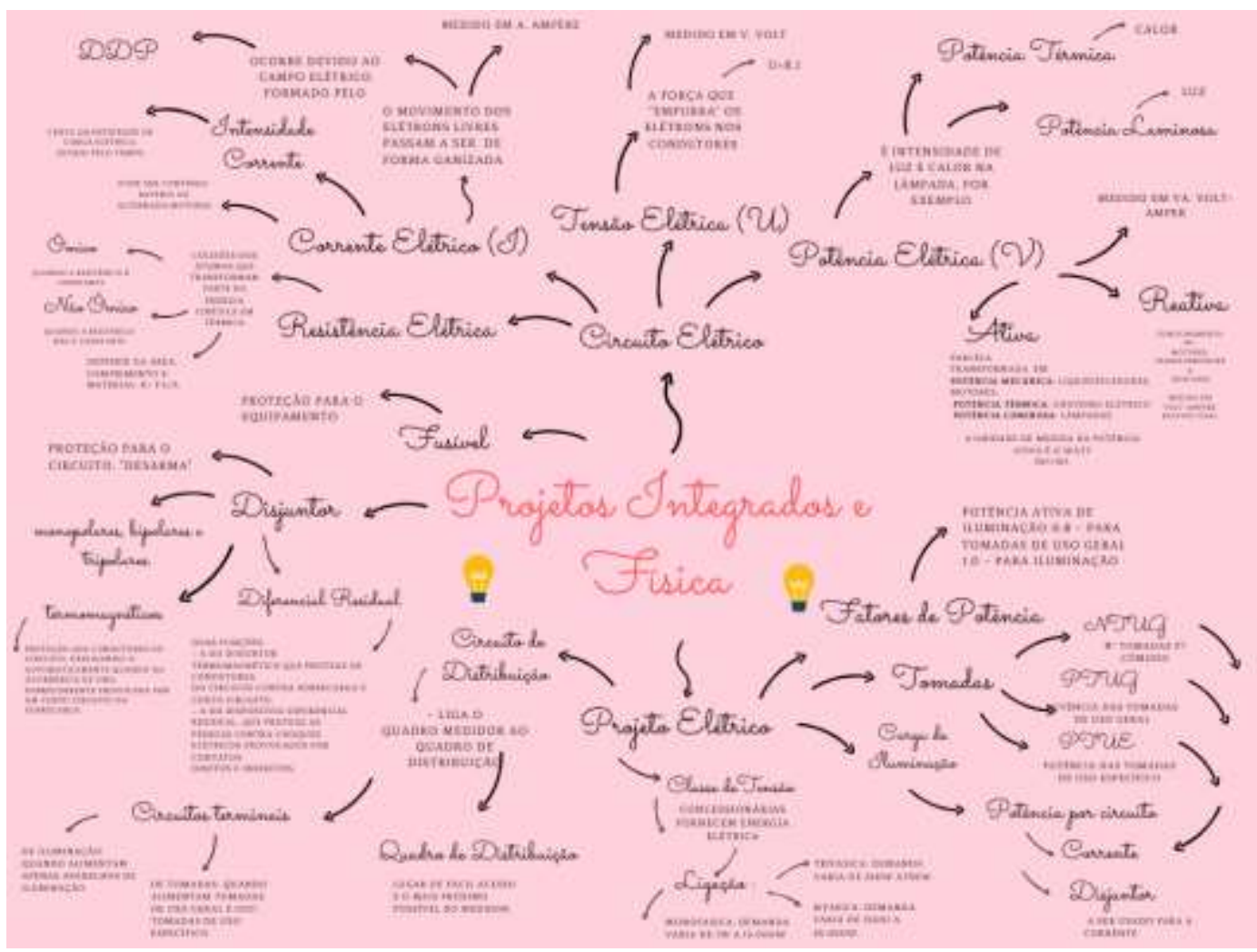

Fonte: Estudante A15.

A Figura 4 apresenta um bom número de conceitos, entretanto, o autor o apresenta de forma independente, desconexa, esquecendo-se dos conectores. Quando estes aparecem, na maior parte das vezes as relações correspondem à definição teórica do conceito, sem explorar relações. Também, o mapa separa as disciplinas, não trazendo relações cruzadas entre os conceitos, enfraquecendo o caráter integrado dos conteúdos desenvolvidos.

O mapa apresentado na Figura 5 também apresenta um número significativo de conceitos, entretanto não os relaciona de forma clara. Diferentemente do anterior, este faz uma maior integração dos conceitos, porém ainda não os conecta por termos suficientes. 
Research, Society and Development, v. 10, n. 3, e15310313296, 2021

(CC BY 4.0) | ISSN 2525-3409 | DOI: http://dx.doi.org/10.33448/rsd-v10i3.13296

Figura 5. Mapa conceitual sobre eletricidade categorizado como parcialmente satisfatório.

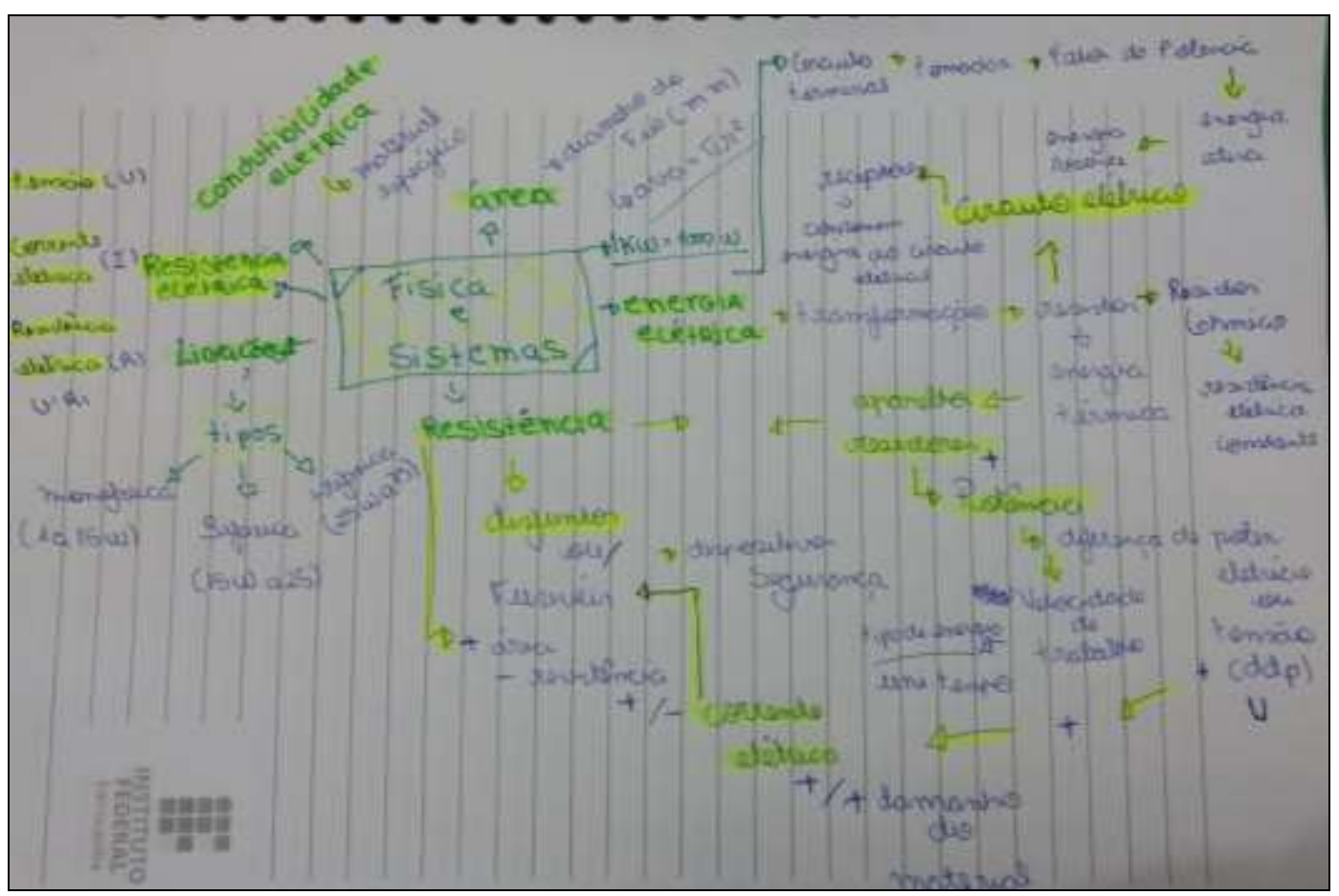

Fonte: Estudante A28.

As Figuras 6 e 7 correspondem a mapas conceituais insatisfatórios.

Figura 6. Mapa conceitual sobre eletricidade categorizado como insatisfatório.

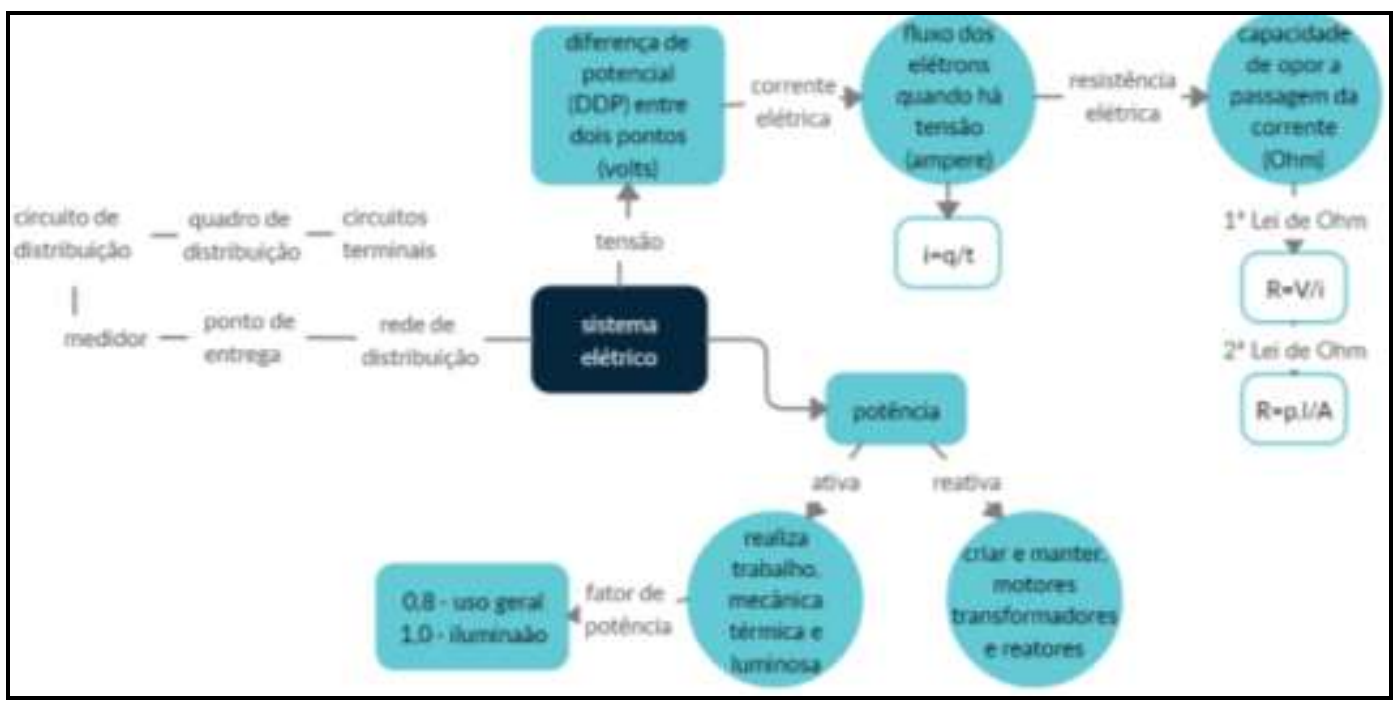

Fonte: Estudante A06.

O mapa apresentado na Figura 6 classifica-se como insatisfatório porque apresenta um número pequeno de conceitos, de ambas as disciplinas, a integração dos conceitos é insuficiente, relacionando os conceitos de forma a excluir elementos conectivos. No entanto, o que atua como termo conectivo são os conceitos principais trabalhados. Quanto às normas técnicas, não contempla elementos técnicos, os quais são importantes quando se fala no projeto elétrico. 
Figura 7. Mapa conceitual sobre eletricidade categorizado como insatisfatório.

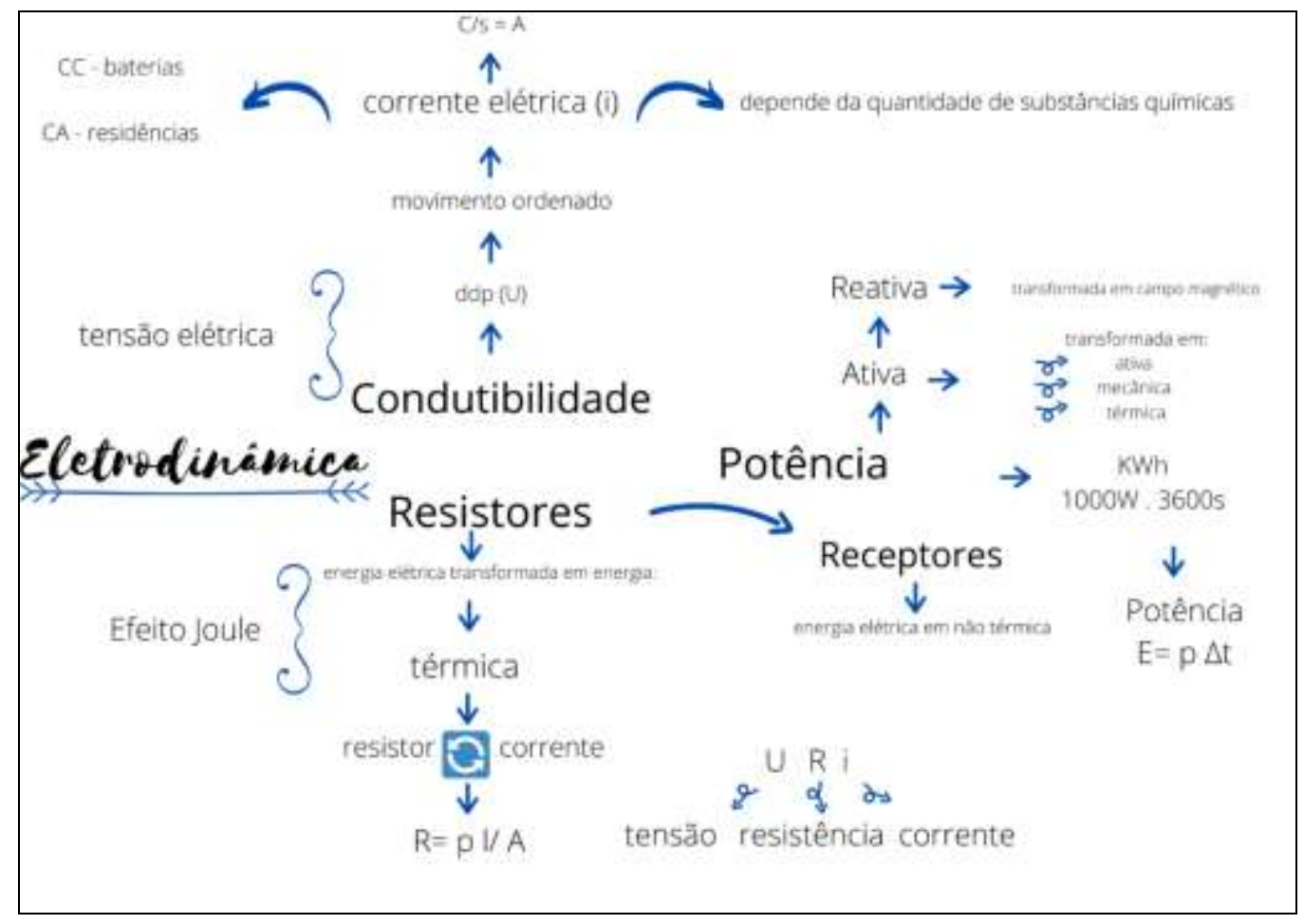

Fonte: Estudante A25.

Como se vê na figura acima, embora alguns conceitos sejam conectados, eles carecem de conectivos. Ainda, a maneira pela qual se dispôs os conceitos dá a impressão de que alguns deles foram locados aleatoriamente no mapa, por não possuírem uma procedência ou conexão com outro qualquer. O conceito de integração também foge em parte deste mapa, pois os assuntos nele tratados quase que excluíram a existência de assuntos técnicos pertencentes à disciplina de sistemas prediais.

Os mapas classificados como parcialmente insatisfatórios e insatisfatórios podem indicar: (a) dificuldade de entendimento conceitual integrado no trabalho interdisciplinar, uma vez que esta é uma abordagem diferente apresentada aos estudantes, ante as aulas tradicionais; (b) que a organização do conhecimento é idiossincrática, refletindo num conjunto de relações estabelecidas em determinado espaço-tempo; (c) a necessidade de mais assessoramentos parciais na elaboração dos mapas, no sentido de ajudar a tornar mais explícita as relações conceituais aos estudantes e; (d) que a complexidade em se habituar com o ensino remoto, imposto pela pandemia do Covid-19, dificultou a construção do conhecimento numa perspectiva dialógica e participativa.

Ainda assim, aproximadamente $65 \%$ dos estudantes tiveram mapas satisfatórios ou parcialmente satisfatórios, o que indica indícios de aprendizagem significativa dos conceitos e suas relações. Isso é válido no sentido que a avaliação dos mapas foi qualitativa, buscando uma "visualização da organização conceitual que o aprendiz atribui a um dado conhecimento" (Moreira, 2016, p. 6).

\section{Projeto Elétrico Residencial}

O projeto elétrico residencial, construído de forma individual pelos estudantes, foi entregue em duas etapas. A primeira entrega correspondeu ao croqui da planta baixa $\operatorname{cotada}^{7}$ de suas residências, indicando os elementos elétricos de cada cômodo, tais como pontos de luz, tomadas de uso geral e de uso específico, principais aparelhos elétricos, com a respectiva

7 Planta baixa ou planta de edificação é um desenho obtido pela intersecção de um plano horizontal de corte a uma altura de aproximadamente $1,5 \mathrm{~m}$ do piso de referência (Ferreira, 2008, p. 11). 
potência, além da identificação de quantos circuitos elétricos existem na residência e o valor do disjuntor que protege cada um deles. Juntamente com o croqui, foi entregue o memorial de cálculo, o qual deveria conter o dimensionamento da potência de iluminação, número mínimo de tomadas de uso geral e específico, bem como suas potências, atendendo os critérios da NBR 5410 (ABNT, 2004). O memorial também deveria apresentar uma divisão das instalações elétricas em circuitos elétricos, definindo os devidos valores da corrente elétrica de cada disjuntor.

Nessa primeira etapa, 07 estudantes entregaram a tarefa de maneira satisfatória, com todas as informações solicitadas e de acordo com a NBR 5410. O Quadro 1 mostra o memorial de cálculo realizado pelo estudante A17. As siglas que aparecem significam: número de tomadas de uso geral ( $\mathrm{N}^{\circ} \mathrm{TUG}$ ), potência ativa das tomadas de uso geral (PTUG ativa), que corresponde à potência que efetivamente realiza trabalho (corresponde a $80 \%$ da potência atribuída às tomadas de uso geral) e potência das tomadas de uso específico (PTUE), que é representado pela potência dos aparelhos considerados.

Quadro 1. Memorial de cálculo do projeto elétrico residencial.

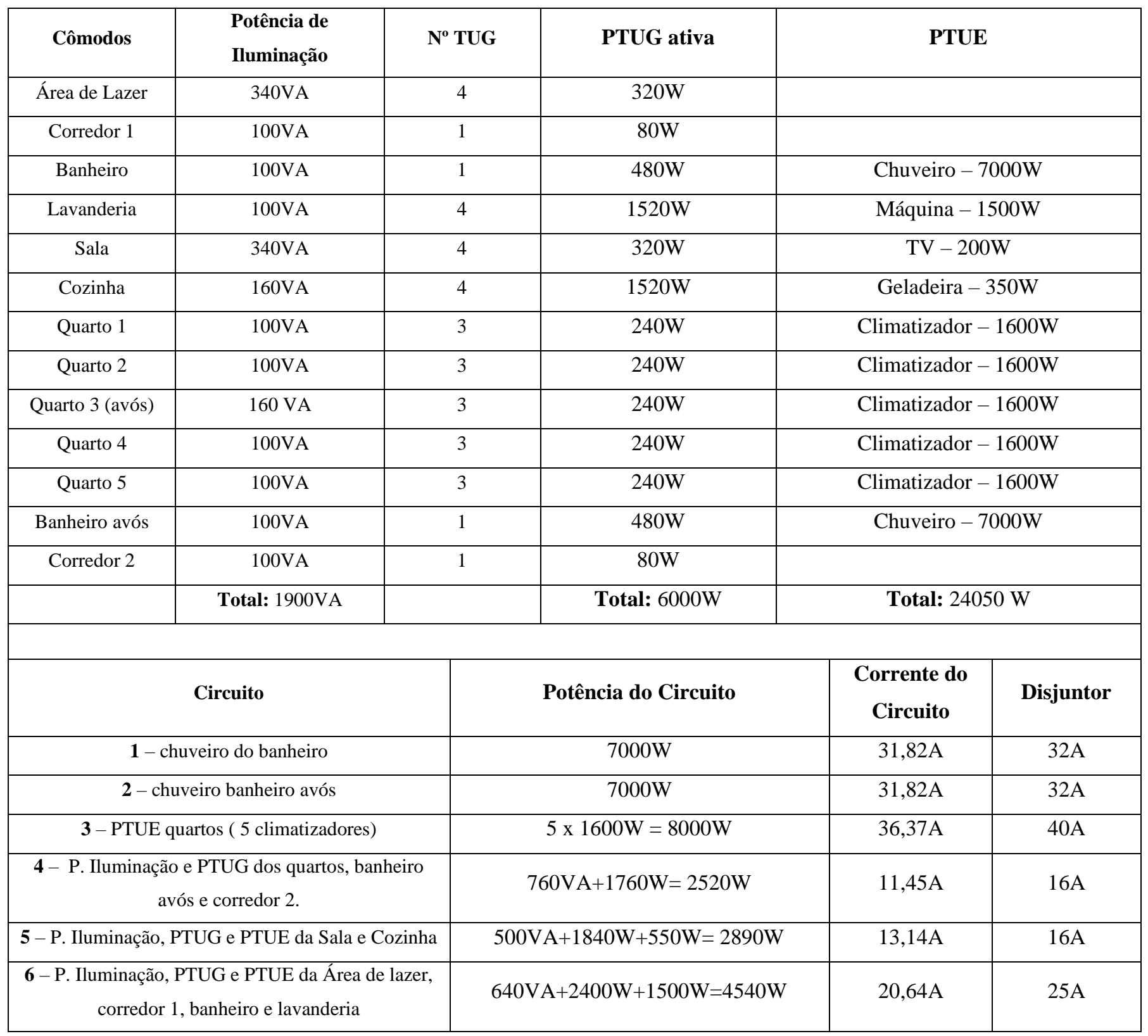

Fonte: Estudante A17. 
Outros 15 estudantes realizaram essa primeira parte do projeto de forma parcialmente satisfatória. Os principais erros cometidos por esses estudantes foram relacionados aos cálculos do número de tomadas de uso geral, a partir da norma técnica, o que implica automaticamente em erro na determinação da potência total das tomadas de uso geral. Consequentemente leva a erros na divisão da instalação em circuitos e sua correte elétrica. Ainda que pareça um erro simples, ele modifica todo o projeto elétrico, podendo resultar em acidentes, caso seja executado.

Os demais 07 estudantes entregaram a primeira parte do projeto com muitos erros, inconsistências e falta de informações. Quatro estudantes desses não apresentaram o croqui da planta baixa com as dimensões dos cômodos, o que impossibilita a correção do memorial de cálculos. Os outros 03 estudantes, apesar de terem apresentado este croqui, não seguiram corretamente a NBR 5410 para o dimensionamento dos circuitos.

Esses 22 estudantes que tiveram algum erro na elaboração dessa primeira etapa do projeto elétrico receberam um maior número de orientações sobre aspectos que precisavam ser corrigidos. Essa etapa de orientação é importante no desenvolvimento da UEPS considerando o princípio da aprendizagem pelo erro (Moreira, 2012), que considera que não há nada de errado em errar; pelo contrário, o sujeito aprende mediante seus erros. Mas, para isso, ele precisa se dar conta do seu erro e que caminhos pode tomar para corrigi-lo.

$\mathrm{Na}$ segunda e última etapa de construção do projeto elétrico, os estudantes entregaram a versão completa do mesmo, contendo o memorial de cálculo corrigido (como aquele mostrado no Quadro 1), a divisão e o dimensionamento dos circuitos terminais e disjuntores, o dimensionando do circuito de distribuição, dos condutores e dos eletrodutos, além da representação gráfica em planta baixa do projeto. Também, entregaram uma análise comparativa entre a instalação elétrica existente em suas casas e a que por eles foi calculada e projetada. Depois de vários momentos de assessoramento, a versão final do projeto elétrico foi enviada de forma satisfatória por oito estudantes, de forma parcialmente satisfatória por quinze estudantes e insatisfatoriamente por seis estudantes.

Dentre os estudantes que tiveram seus projetos classificados como insatisfatórios, destacam-se A06 e A21. O primeiro não fez o comparativo entre o real instalado na residência e o projetado e nem o dimensionamento do circuito de distribuição. Também, não cotou e/ou não representou os eletrodutos e os condutores do chuveiro. Ainda, não dimensionou corretamente a fiação utilizada para as tomadas, uma vez que o condutor de secção $1,5 \mathrm{~mm}^{2}$ só é utilizado quando o circuito é exclusivo de iluminação. Além disso, não representou corretamente as ligações dos fios retorno e fase em algumas tomadas.

O segundo estudante (A21) não teve evolução em relação aos assessoramentos e continuou com erros no cálculo das tomadas de uso geral e específico, o que resulta em erros significativos no projeto final. Também, na planta baixa não identificou as peças da casa e suas dimensões. Além disso, faltou o dimensionamento dos condutores, dos eletrodutos e do circuito de distribuição e o comparativo do projeto com o real instalado. A Figura 8 mostra a planta baixa do estudante A21, com essas lacunas apontadas. 
Figura 8. Planta baixa do projeto elétrico residencial.

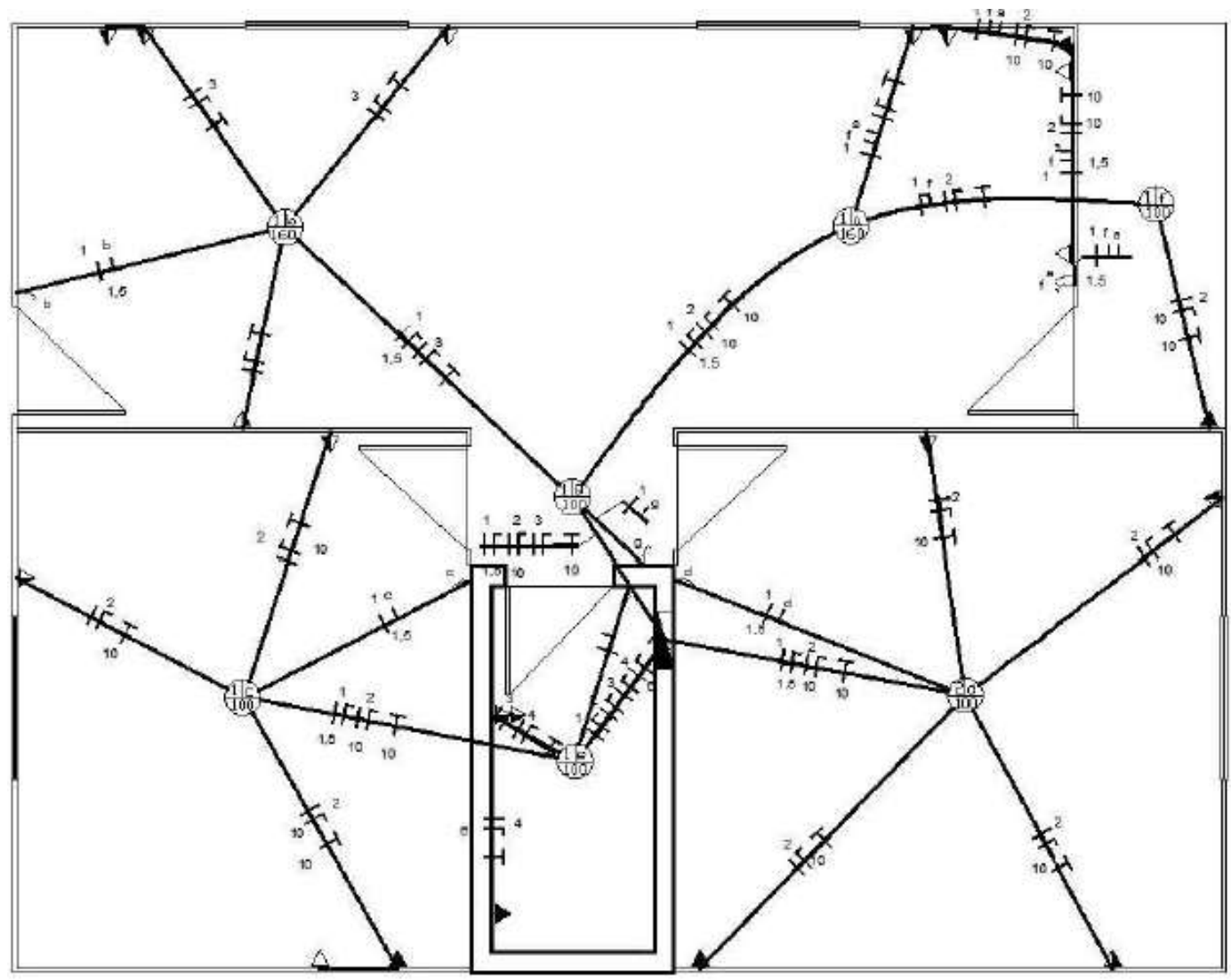

Fonte: Estudante A21.

Dentre os estudantes que tiveram seus projetos avaliados como parcialmente satisfatórios, destacam-se A03 e A18. O estudante A18 apenas não fez o dimensionamento do circuito de distribuição e em alguns pontos de iluminação representou adequadamente os condutores. Apesar disso, fez um comparativo muito bom entre o projeto e a instalação real da residência, indicando indícios de aprendizagem significativa dos conceitos trabalhados nas disciplinas. Em seu comparativo, ele destaca que

as maiores mudanças entre projeto e realidade na residência ocorrem nos disjuntores pois, em projeto, conforme os cálculos, seria adequada a presença de quatro disjuntores no segundo piso da casa para atender todas as necessidades com segurança. Na realidade, existem apenas dois que acabam desarmando muitas vezes em que vários eletrodomésticos estão ligados. Como a casa recebeu uma ampliação, acredito que a instalação presente fosse suficiente para atender apenas a casa anterior a ampliação. Com a ampliação, a instalação elétrica deveria ter sido modificada, o que não aconteceu. (...) Outro ponto importante para ser ressaltado e as tomadas e a iluminação. Com o projeto se é capaz de atender a várias necessidades não atendidas na realidade. Muitas vezes, não há tomadas suficientes nos cômodos da casa, o que gera a necessidade de uso de "T" nos eletrodomésticos. Com o projeto, podemos dividir as tomadas conforme a necessidade dos ambientes, fazendo com que não seja necessário o uso dos " $T$ ” e de extensões (estudante A18).

O projeto do estudante A03 teve um superdimensionamento do disjuntor do circuito de distribuição; em vez de um disjuntor de 60 A, o estudante estimou um de valor 100 A, pois utilizou a PTUG (potência das tomadas de uso geral) duas 
vezes na estimativa da potência do circuito de distribuição. Por segurança, é possível de acontecer isso, embora o contrário traga muitos riscos ao circuito elétrico. No entanto, este superdimensionamento resulta em gastos adicionais desnecessários. Em relação à planta baixa da residência, algumas tomadas de uso específico não foram representadas (ex: climatizador de ar nos dormitórios). Também, a tomada do quarto 1 passa por uma janela, o que é incorreto, já que não se passa eletrodutos nem condutores por aberturas.

Apesar do estudante A03 não ter especificado os cômodos da residência em sua planta baixa, diferentemente do estudante A21, utilizou uma legenda ao longo do projeto que permite identificar essas peças. A Figura 9 ilustra a planta baix a e a legenda utilizada pelo estudante $\mathrm{A} 03$. O detalhe em amarelo desta figura corresponde à tomada que o estudante representou em uma janela. Apesar desses erros cometidos na elaboração do projeto elétrico, pode-se inferir indícios de aprendizagem significativa em relação ao projeto elétrico e os respectivos conceitos necessários à sua construção.

Figura 9. Representação da planta baixa da residência.

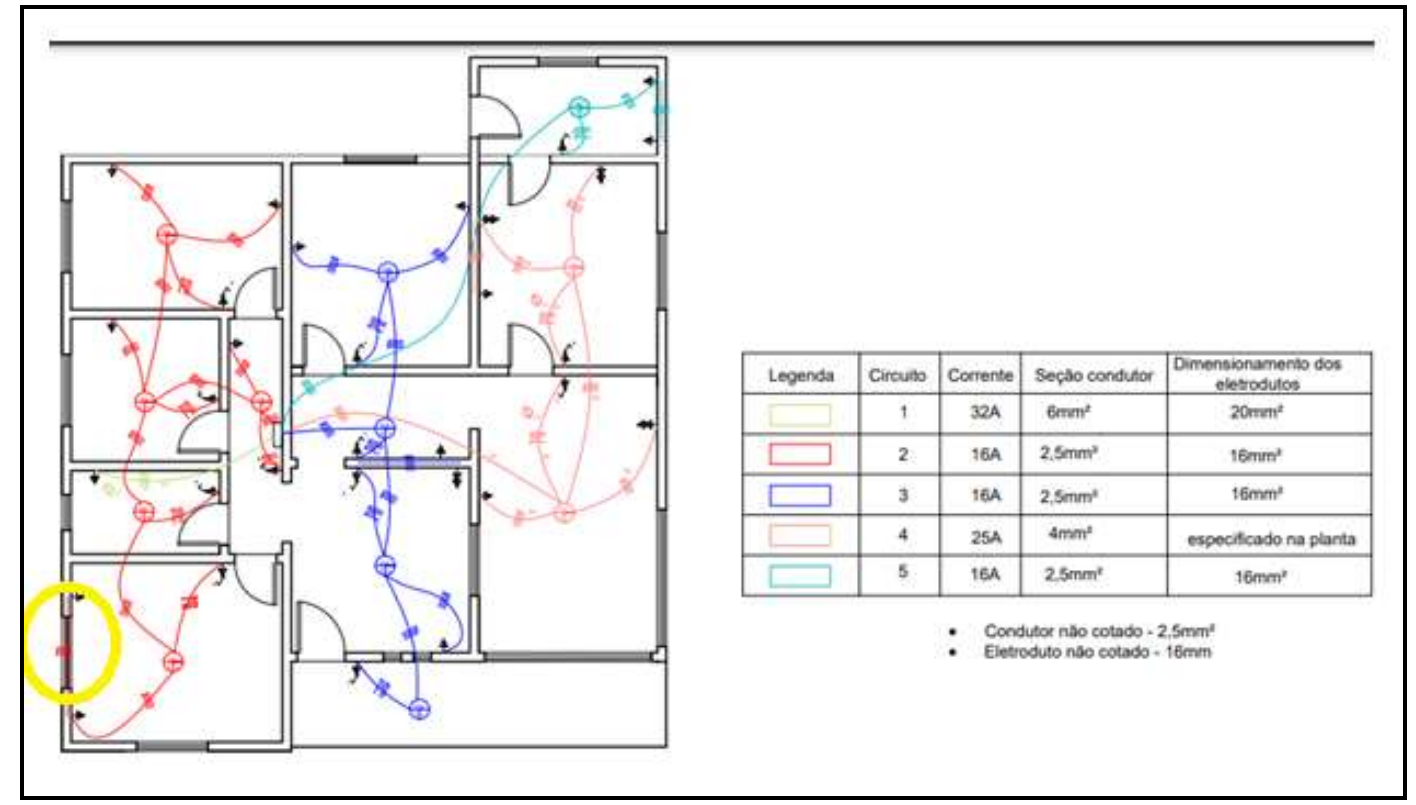

Fonte: Estudante A03.

Dentre os estudantes que entregaram projetos elétricos de forma satisfatória, destaca-se o estudante A16. Este realizou todas as etapas do projeto corretamente, desde o levantamento dos condicionantes, que envolvem as dimensões de cada cômodo, seu uso, equipamentos elétricos a serem instalados, o dimensionamento da potência de iluminação, do número de tomadas de uso geral e específico e suas potências, divisão do sistema elétrico em circuitos, dimensionamento dos disjuntores, eletrodutos e condutores até a graficação do projeto em um programa de desenho assistido por computador. A Figura 10 traz a planta baixa da residência deste estudante, com a representação das tomadas, dos pontos de iluminação, das ligações, da divisão dos circuitos e o dimensionamento dos condutores e eletrodutos. 
Figura 10. Representação da planta baixa da residência.

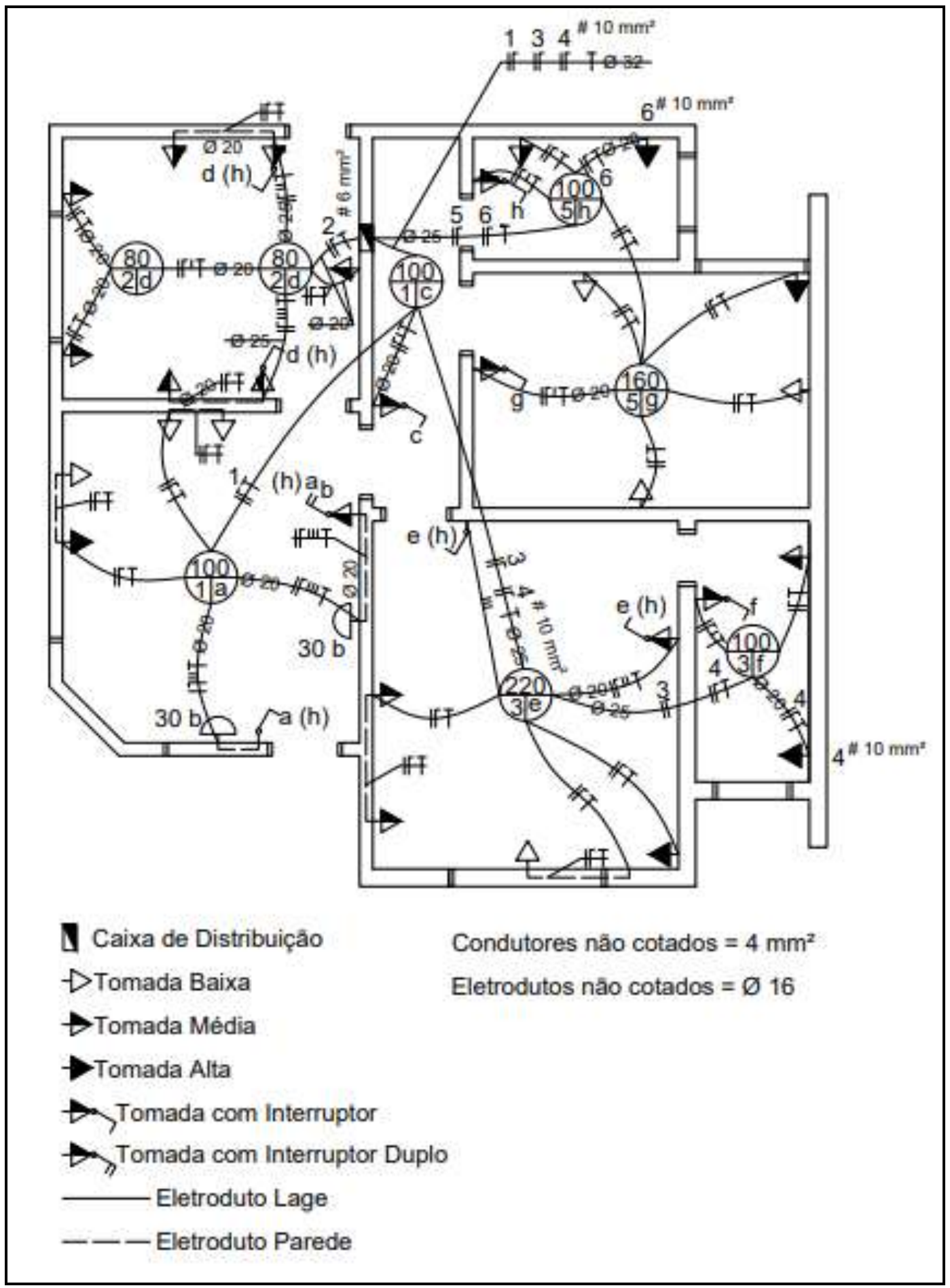

Fonte: Estudante A16.

A Figura 11 apresenta o dimensionamento do circuito de distribuição e dos condutores a partir dos valores de potência e corrente elétrica de cada cômodo. Essas figuras ilustram indícios de aprendizagem significativa do estudante A16 e daqueles que tiveram seus projetos elétricos elaborados satisfatoriamente. 
Figura 11. Dimensionamento do circuito de distribuição e dos condutores.

\begin{tabular}{|c|c|c|c|c|}
\hline cincuitos & comobos & POTENCIA & CORRENTE & DISJUNTOR \\
\hline 01 & $\begin{array}{c}\text { Sala } \\
\text { Crouilapiao }\end{array}$ & $2300 \mathrm{~W}$ & $10.82 \mathrm{~A}$ & 16 A (Marca Desconthecida) \\
\hline 02 & Cozinha & B.560 W & $30.86 \mathrm{~A}$ & 40 A (Marca Desconhecoda) \\
\hline 03 & $\begin{array}{l}\text { Dorminbrio } 01 \\
\text { Sanitarne o1 }\end{array}$ & $4.140 \mathrm{~W}$ & $18,82 \mathrm{~A}$ & 20.A (Marca Desconthecida) \\
\hline 04 & Cluveire Sanitario o1 & $7000 \mathrm{w}$ & $31.82 \mathrm{~A}$ & 32. A (Marca Desconhecida) \\
\hline os & $\begin{array}{l}\text { Dormitiovio } 02 \\
\text { Sanianio } 02\end{array}$ & $4.060 \mathrm{w}$ & $\$ 8,55 \mathrm{~A}$ & 20 A (Marca Desconhecida) \\
\hline 06 & Chuveiro Sanitario 12 & $7.000 \mathrm{w}$ & $31,82 \mathrm{~A}$ & 32 A (Marca Desconhecida) \\
\hline \multicolumn{3}{|c|}{ Circuite de Distribuiço } & & \\
\hline \multicolumn{2}{|c|}{ Potencia } & $210015 \mathrm{~W}$ & & \\
\hline Corrente & \multicolumn{2}{|r|}{$95,5 \mathrm{~A}$} & & \\
\hline \multicolumn{3}{|c|}{ Dimensionamento dos Condutores } & & \\
\hline Circuilto & Cortente & Seccaso Condutor Fase & & \\
\hline 01 & 16 & $4 \mathrm{~mm} \mathrm{~m}^{2}$ & & \\
\hline$\omega 2$ & 40 & $6 \mathrm{~mm}^{2}$ & & \\
\hline 03 & 20 & $4 \mathrm{~mm}$ & & \\
\hline 04 & 32 & $10 \mathrm{~mm}^{t}$ & & \\
\hline 05 & 20 & 4 man" & & \\
\hline 06 & 32 & $10 \mathrm{~mm}^{4}$ & & \\
\hline
\end{tabular}

Fonte: Estudante A16.

Do resultado atingido, reafirma-se a importância dos momentos de assessoramento, uma vez que a maior parte dos estudantes (79\%) concluíram seus projetos de forma satisfatória (08 estudantes) ou parcialmente satisfatória (15), enquanto $21 \%$ dos estudantes (06 deles) o fizeram de forma insatisfatória. Esse resultado positivo exprime uma forte relação com efetividade do trabalho interdisciplinar desenvolvido, considerando que em $70 \%$ das aulas, ambos os professores estavam juntos na sala, desenvolvendo os conceitos e fazendo os assessoramentos. Isso favorece que os estudantes percebam essa integração e pensem de forma menos fragmentada, uma vez que precisam fazer a relação dos conceitos das duas disciplinas para darem conta das tarefas, já que as disciplinas são complementares.

\section{Considerações Finais}

Uma Unidade de Ensino Potencialmente Significativa acontece do desenvolvimento de diversas etapas, com vistas à aprendizagem significativa de conceitos. Para tanto, o conhecimento prévio dos estudantes é o fator principal para a diferenciação e enriquecimento dos conceitos. Apesar dos diferentes passos elaborados, o enfoque deste escrito é analisar indícios de aprendizagem significativa na construção de mapas conceituais e de um projeto elétrico residencial.

Os mapas conceituais, analisados a partir da integração das duas disciplinas, permitiram afirmar que aproximadamente $65 \%$ dos estudantes exprimiram indícios de aprendizagem significativa. Isso se justifica pelo fato de terem apresentado um bom número de conceitos, ligações pertinentes/corretas entre eles e relações entre as disciplinas. Salienta-se que os mapas são idiossincráticos e exprimem as relações que os estudantes fazem dos conceitos aprendidos. Nesse sentido, eles também são basilares para a reflexão sobre a forma que estamos ensinando.

Sobre o projeto elétrico residencial, $79 \%$ dos estudantes possibilitaram inferir indícios de aprendizagem significativa. A articulação entre as duas disciplinas favoreceu o entendimento e o emprego dos conceitos em um trabalho técnico, que prepara os jovens para o mundo do trabalho, ratificando a importância da proposta de currículo integrado dos IFs. Se os indícios de aprendizagem significativa de conceitos podem ser evidenciados em situações diferentes daquelas em que foram ensinados, pode-se afirmar que a maior parte dos estudantes conseguiu utilizá-los no cumprimento das normas técnicas. 
Vale ressaltar que esses dois instrumentos de avaliação foram acontecendo durante a crise sanitária do Covid-19 e, portanto, com a condição de isolamento social. Devido a isso, as aulas, assessoramentos e conversas ocorreram com o auxílio da internet e softwares gratuitos. A comunicação se dava instantaneamente por meio do aplicativo de chat WhatsApp e as aulas e assessoramentos, mediante Google Meet, de maneira síncrona e pelo Sistema Integrado de Gestão da instituição.

Mesmo com a limitação física imposta pela pandemia, o desenvolvimento de aulas integradas foi fundamental para o êxito da UEPS e para o favorecimento da aprendizagem significativa. Diversas aulas e assessoramentos aconteceram com os dois professores no mesmo espaço e tempo, o que reflete a parceria e confiança no trabalho de ambos os professores.

Sendo o primeiro autor deste artigo um sujeito participante da pesquisa enquanto estudante, foi possível perceber e participar de diálogos extra aula. A partir destes, é razoável afirmar que os estudantes perceberam a complementaridade das disciplinas, a partir do planejamento e realização das aulas integradas. Em alguns momentos, tornava-se difícil a classificação de qual era a disciplina que estava sendo trabalhada, o que reforça a importância da integração de conhecimentos parciais com vistas à totalidade do conhecimento. E esse é o caminho para minimizar e/ou superar o pensamento positivista da superespecialização.

Com vistas ao aperfeiçoamento da Unidade de Ensino Potencialmente Significativa, uma sugestão de trabalho futuro, considerando o retorno às atividades letivas presenciais, é a realização de atividades práticas de laboratório para explorar alguns conceitos da eletricidade, como potência, resistência, tensão e corrente elétrica. Nessa perspectiva, poderia ser instalado algum dispositivo ligado ao circuito, simulando uma sobrecarga que faça o disjuntor desarmar.

\section{Agradecimentos}

Os autores agradecem ao Instituto Federal de Educação, Ciência e Tecnologia e ao CNPq pela bolsa de pesquisa.

\section{Referências}

Associação Brasileira de Normas Técnicas (2004). NBR 5410: instalação elétricas de baixa tensão.

Ausubel, D. P. (2003). Aquisição e retenção de conhecimentos: uma perspectiva cognitiva. Tradução Lígia Teopisto. Editora Plátano.

Ausubel, D. P. (1968). Educational Psychology: a cognitive view. Holt, Rinehart \& Winston.

Cruz Sobrinho, S. (2017). Diretrizes institucionais e a perspectiva da integração curricular no IF Farroupilha. In: Araújo, A. C. \& Silva, C. N. N. (Orgs.). Ensino Médio Integrado no Brasil: fundamentos, práticas e desafios. Editora IFB.

Dália, J. M. T. \& Frazão, G. A. (2017). Para além do ensino integrado: experiências, possibilidades e desafios da articulação entre ensino, pesquisa e extensão no currículo. In: Araújo, A. C. \& Silva, C. N. N. (orgs.). Ensino médio integrado no Brasil: fundamentos, práticas e desafios. Brasília: Ed. IFB.

Dorneles, P. F. T., Araújo, I. S. \& VEIT, E. A. (2006). Simulação e modelagem computacionais no auxílio à aprendizagem significativa de conceitos básicos de eletricidade: parte I - circuitos elétricos simples. Revista Brasileira de Ensino de Física, 28(4), 487-496.

Ferreira, P. (2008). Desenho de Arquitetura. Imperial Novo Milênio.

Gil, A. C. (2002). Como elaborar projetos de pesquisa. (4a ed.), Atlas.

Moreira, M. A. (2012). ¿Al final, qué es aprendizaje significativo? Revista Qurriculum, 25, 29-56.

Moreira, M. A. (2016). Mapas conceituais, diagramas V, organizadores prévios, negociação de significados e unidades de ensino potencialmente significativas. Porto Alegre, RS: UFRGS.

Moreira, M. A. (2011). Unidades de enseñanza potencialmente significativas - UEPS. Aprendizagem Significativa em Revista, 1(2), $43-63$.

Moreira, M. A. \& Masini, E. A. F. S. (1982). Aprendizagem significativa: a teoria de David Ausubel. Moraes.

Novak, J. D. \& Cañas, A. J. (2010). A teoria subjacente aos mapas conceituais e como elaborá-los e usá-los. Práxis Educativa, 5(1), 9-29.

Pereira, A. S. et al. (2018). Metodologia da pesquisa científica. UFSM.

Pimentel, M., \& Carvalho, F. S. P. (2020). Princípios da Educação Online: para sua aula não ficar massiva nem maçante! SBC Horizontes. 
Research, Society and Development, v. 10, n. 3, e15310313296, 2021

(CC BY 4.0) | ISSN 2525-3409 | DOI: http://dx.doi.org/10.33448/rsd-v10i3.13296

Pozo, J. I. \& Crespo, M. A. G. (2009). A aprendizagem e o ensino de ciências: do conhecimento cotidiano ao conhecimento científico. (5a ed.), Artmed.

Silva, J. C. (2018). Abordagem interdisciplinar no ensino da física térmica em um curso técnico em edificações a partir da construção de um forno solar. Tese (doutorado) - Universidade Federal de Santa Maria, Centro de Ciências Naturais e Exatas, Programa de Pós-Graduação em Educação em Ciências: Química da Vida e Saúde, Santa Maria, RS, 167 p.

Silva, J. C. et al. (2020). Fortalecimento da integração curricular em um curso técnico integrado em edificações. In: Cruz Sobrinho, S. \& Plácido, R. L. (Orgs.). Educação profissional integrada ao ensino médio. João Pessoa: IFPB, 429-456.

Silveira, F. L., Moreira, M. A. \& Axt, R. (1989). Validação de um teste para verificar se o aluno possui concepções científicas sobre corrente elétrica em circuitos simples. Ciência e Cultura, 41(11), 1129-1133.

Solano, F. et al. (2002). Persistencia de preconcepciones sobre los circuitos electricos de corriente continua. Revista Brasileira de Ensino de Física, 24(4), $460-470$. 